\title{
Urinary Sodium and Potassium excretion among Year 4 pupils in Choshi city, Japan
}

\author{
A. Nishide ${ }^{1}$, M. Yoshioka ${ }^{2}$, A. Hata ${ }^{1}$ and S. Sato ${ }^{2}$ \\ ${ }^{1}$ Department of Public health, Chiba University, 1-8-1 Inohana,Chuo-ku, Chiba-shi, Chiba-ken, Japan and ${ }^{2}$ Chiba \\ Prefectural Institute of Public Health, 666-2 Nitona-cho, Chuo-ku, Chiba-shi, Chiba- ken, Japan
}

The elementary schools in Choshi city have provided the annual health examination for metabolic syndrome among 4th year pupils in 12 public schools. The age of 4 th year pupils could be considered as the start line for issues that will affect their health condition, such as blood pressure from eating habits and anthropometric features. In addition, a previous study indicated that schoolchildren tend to be more susceptible to health messages and may maintain their diet into the future ${ }^{(1)}$. The aim of the present study was to estimate salt intake and potassium intake by spot urine methods among 4th year pupils in Choshi city, and evaluate the association between salt intake/ potassium intake and blood pressure in that population.

The present study was conducted in Chosi city using the data from the annual health examination for metabolic syndrome in 4th grade elementary school students in 12 public schools from 13th of November to 18th of November in 2013. All participants (358 participants; boys 193, girls 165) underwent anthropometric measurement (weight, height, obesity index) and the measurement of Systolic blood pressure (SBP) and diastolic blood pressures (DBP) by an automatic sphygmomanometer. Urinary sodium, potassium and creatinine concentrations using the first morning urine specimen were measured, and the $24 \mathrm{hr}$ intake of sodium and potassium were estimated ${ }^{(2,3)}$. Continuous variables were expressed as the mean \pm standard deviation. The estimated 24-hr urinary sodium excretion and other biomarkers among the groups were also compared using an analysis of variables that showed $p$ value of $<0.05$. The association between blood pressure and the biomarkers were analysed by Pearson correlation. The association between the estimated 24-hr urinary sodium, potassium excretion, sodium to potassium ratio and other biomarkers were analysed by Spearman correlation.

The mean values of salt intake were estimated to be $100 \pm 74 \mathrm{mmol}$ per day $(5.9 \pm 4.4 \mathrm{~g}$ per day of salt) total, $106 \pm 93 \mathrm{mmol}(6.2 \pm$ $4.0 \mathrm{~g}$ per day of salt) and $93 \pm 81 \mathrm{mmol}(5.5 \pm 4.8 \mathrm{~g}$ per day of salt) for boys and girls respectively. The mean values of urinary potassium excretion were estimated to be $29 \pm 30 \mathrm{mmol}$ per day (1133 mg $\pm 1157 \mathrm{mg}$ per day of potassium) total, $32 \pm 25 \mathrm{mmol}$ per day $(1263 \mathrm{mg} \pm 1368 \mathrm{mg}$ per day of potassium) and $25 \pm 21 \mathrm{mmol}(980 \mathrm{mg} \pm 640 \mathrm{mg}$ per day of potassium) for boys and girls respectively. The mean value of sodium to potassium ratio was $4.2 \pm 2.2$ total, $4.1 \pm 2.3$ and $4.3 \pm 2 \cdot 1$ for boys and girls respectively. Only $33 \cdot 0 \%$ (33.7 \% and $32.1 \%$ for boys and girls respectively) of the participants for the sodium to potassium ratio were below 3.0. A significant positive correlation was found between SBP and estimated $24 \mathrm{hr}$ urinary sodium excretion (log); as well as, SBP and urinary potassium excretion ( $\log$ ) after adjustment for gender ; however, no significant correlations were found between SBP and sodium/potassium ratio. The result shows that most pupils have not met the below 3.0 standard in sodium to potassium ratio. In addition, significant correlation between SBP and estimated $24 \mathrm{hr}$ urinary sodium excretion (log) was found in these 4th year pupils.

1. Murata M., (2013) Activity Report Tokyo Health Service Association 42, 44-52.

2. Moriyama M., Saito H., Kabuto M (1987) J Nutr Sci Vitaminol 3, 185-93.

3. Morinaga Y., Tsuchihashi T., Ohta Y et al., (2011) Hypertens Res 34.7, 836-9. 